\title{
Adaptation of the free bag technique to evaluate the use of the nitrogenous component of feeds in the large intestine of the pony
}

\author{
C Cordelet, F Faurie, JL Tisserand \\ Laboratoire de Recherches de la Chaire de Zootechnie de l'ENSSAA, \\ 26, bd Dr-Petitjean, 21000 Dijon, France
}

In order to adapt to the horse the free bag technique already perfected on ruminants (cows and sheep; Vérité et al, 1987), we used 4 male adult ponies, weighing approximately $180 \mathrm{~kg}$, with a permanent cecum cannula, fed in individual stalls twice a day $(8: 00$ am and $5: 00 \mathrm{pm}) 4.5 \mathrm{~kg}$ of first cutting cocksfoot alfalfa hay. Water and a mineral block were available ad libitum. The feed was enclosed in a free bag made of a nylon fiber material $(46 \mu \mathrm{m})$ and was introduced through the cecum cannula either directly or after pepsin predigestion (6 $\mathrm{h}$ in a pepsin solution: $2 \mathrm{~g} / \mathrm{l}$ of $0.1 \mathrm{~N}$ $\mathrm{HCl}$ ). It was recovered in the feces. The quantity of nitrogen found in the bag enabled us to evaluate the quantity of alimentary nitrogen really degraded in the large intestine (de Boer et al, 1987).

First we compared 3 sizes of bags filled with alfalfa hay. They measured $2.5 \times$ $3 \mathrm{~cm}$ with $0.35 \mathrm{~g}$ of substratum, $2.5 \times 6 \mathrm{~cm}$ with $0.8 \mathrm{~g}$ of substratum and $3 \times 11 \mathrm{~cm}$ with $1.7 \mathrm{~g}$ of substratum, respectively. The 32 measures of DM disappearance gave the following mean results: small bags: $30.0 \pm 3.3$; middle-sized bags: $31.4 \pm 5.4$; large bags: $38.1 \pm 2.7$. We consequently chose to introduce the large bags at 5:00 pm to evaluate nitrogen digestion in the large intestine, either by introducing the bag containing the feed directly or after pepsin digestion. We studied 4 feeds: alfalfa hay, soya cake, meat flour and fish flour. Our first observations show a close relationship between disappearance in the large intestine after pepsin digestion and digestibility measured in vivo (table I).

de Boer G, Murphy JJ, Kennely JJ (1987) J Dairy Sci 70, 977-982

Vérité R, Michalet-Doreau $B$, Chapoutot $P$, Peyraud JL, Poncet C (1987) Bull Tech CRZV Theix INRA 70, 19-34

Voigt J, Piatkowki B, Engelmann H, Rudolph E (1985) Arch Tierernachr 35, 555-562

Table I. In sacco nitrogen degradability (Snd) in the cecum directly or after pepsin digestion (pd).

\begin{tabular}{llccc}
\hline Feed & TN \% DM & Snd & Snd $+\rho d$ & $p d$ \\
\hline Alfalfa hay & 12.9 & $44.5 \pm 3.2$ & $71.6 \pm 3.2$ & 23.5 \\
Soya cake & 50.7 & $86.0 \pm 2.0$ & $88.6 \pm 2.0$ & 56.7 \\
Meat flour & 61.9 & $66.9 \pm 3.3$ & $80.8 \pm 2.7$ & 29.2 \\
Fish flour & 69.3 & $58.3 \pm 5.4$ & $82.3 \pm 3.2$ & 50.4 \\
\hline
\end{tabular}

